\title{
Early predictors of PIH: serum $\beta$-HCG and lipid profile
}

\section{Shanmugavadivu, K. P. Mohona Sundari*, Parimala Devi}

\begin{abstract}
Department of Obstetrics and Gynecology, Govt. Mohan Kumaramangalam Medical College Hospital, Salem, Tamil
\end{abstract} Nadu, India

Received: 17 October 2016

Accepted: 25 October 2016

\section{*Correspondence:}

Dr. K. P. Mohona Sundari,

E-mail: m72sundari@yahoo.in

Copyright: ( ) the author(s), publisher and licensee Medip Academy. This is an open-access article distributed under the terms of the Creative Commons Attribution Non-Commercial License, which permits unrestricted non-commercial use, distribution, and reproduction in any medium, provided the original work is properly cited.

\section{ABSTRACT}

Background: The objective of the study was to evaluate $\beta-\mathrm{HCG}$ and lipid profile in early second trimester and analyse whether these parameters can be used as predictors of PIH.

Methods: 180 antenatal women in second trimester (14-20 weeks) attending antenatal clinic were taken as study population. Serum triglycerides, total cholesterol, LDL, VLDL, HDL, $\beta$-hCG was measured. All patients were followed till delivery and observed for development of PIH. Results was evaluated and analysed statistically.

Results: Out of 180 cases, 173 cases were evaluated. Among 173 cases, $87.86 \%$ were normotensive. $8.09 \%$ developed mild PIH and $4.05 \%$ developed severe PIH. There was significant increase in values of $\beta$-hCG $(\mathrm{p}<0.001)$ and total cholesterol, triglycerides, low density lipoproteins and very low density lipoprotein $(\mathrm{p}<0.001)$ and significant decrease in values of high density lipoprotein $(\mathrm{p}<0.001)$ in those women who developed PIH.

Conclusions: Measurement of all these parameters in early second trimester can help in predicting PIH. By proper follow up of these patients, early detection and better management of PIH and its complications is possible which would improve the maternal and fetal outcome.

Keywords: $\beta$-HCG, Early predictors of PIH, Lipid profile, PIH

\section{INTRODUCTION}

Hypertensive disorders complicate $5-10 \%$ of all pregnancies. How pregnancy initiates or aggravates hypertension still remains unsolved, despite decades of extensive research. Indeed, hypertensive disorders continues to remain among the most significant and unsolved problems in obstetrics. ${ }^{1}$

In pregnant women, the diagnosis of gestational hypertension is made when blood pressure reaches $140 / 90 \mathrm{~mm} \mathrm{Hg}$ or more for the first time during pregnancy with or without proteinuria. Preeclampsia is identified in $3.9 \%$ of all pregnancies. ${ }^{1}$

Preeclampsia appears to be a culmination of factors that likely involve a number of maternal, placental and fetal factors. Those currently considered important include, placental implantation with abnormal trophoblastic invasion of uterine vessels, immunological maladaptive tolerance between maternal, (placental) and fetal tissues, maternal maladaption to cardiovascular or inflammatory changes of normal pregnancy, genetic factors including inherited predisposing genes as well as epigenetic influences. Measurement of various biological, biochemical and biophysical markers that are involved in the pathophysiology of preeclampsia during early pregnancy has been proposed to predict its development. ${ }^{1}$

Abnormal lipid profile is associated with atherosclerotic cardiovascular dysfunction. The most important feature in preeclampsia is vasospastic phenomenon in kidney, uterus, placenta and brain. Altered lipid synthesis causes decrease in PGI2:TXA2 ratio which is suggested to be an important pathway in pathogenesis in $\mathrm{PIH}{ }^{2}$ 
Heightened insulin resistance occurring in preeclampsia would increase fatty acid mobilization from visceral fat. It promotes over production of VLDL by liver and suppression of post hepatic lipoprotein lipase. It results in increased serum FFA and TGs. The similarity between the lesions of preeclampsia and atherosclerosis has led to speculations of a common pathophysiological pathway. Maternal serum lipids are significantly elevated during pregnancy. Women who develop preeclampsia experience even more dramatic lipid changes. Most studies have shown a preeclampsia-dyslipidemic pattern of increased triglycerides, cholesterol, low density lipoprotein (LDL), and decreased high density lipoprotein (HDL) concentration. ${ }^{2}$

The association of altered lipid profile in essential hypertension is well documented. In early pregnancy there is increased body fat accumulation associated with increased lipogenesis, while in late pregnancy there is accelerated breakdown of fat depots which play an important role in fetal development.

Early pregnancy dyslipidemia is associated with an increased risk of preeclampsia. Women with a history of preeclampsia have significant differences in lipid parameters and an increased susceptibility to lipoprotein oxidation when compared with women who had normal pregnancy. Therefore simple measurements of serum lipid profile may be of good predictive value in preeclampsia.

Women with PIH have hyperplacentosis or an abnormal placentation. Beta subunit of human chorionic gonadotropin ( $\beta$ hCG) is secreted in abundance from placenta. $\beta$ hCG level in mid trimester is elevated in patients with chromosomally normal fetus who later on develop preeclampsia.

\section{METHODS}

This is a prospective study conducted in Govt. Mohan Kumaramangalam medical college and hospital, salem, from August 2014-August 2015. The sample size includes 180 antenatal women in second trimester (14-20 weeks) attending AN clinic.

\section{Inclusion criteria}

180 pregnant, normotensive, non-proteinuric women in early second trimester (14-20 weeks) attending a clinic for regular check up, irrespective of parity and with no associated complications.

\section{Exclusion criteria}

Hypertension Before 20weeks, Diabetes mellitus, Renal Disease, Cardiac Disease, Hepatic Disease, Multiple Pregnancy, Thyroid Disorder, Molar Pregnancy, Congenital Malformation, PIH in previous pregnancy.
$5 \mathrm{ml}$ of venous blood sample drawn from all women after 12 hrs of fasting. Anticoagulant used was EDTA. Serum Triglycerides, total cholesterol was analysed by enzymatic colorimetric method. HDL analysed by precipitation colorimetric method. LDL was calculated by Friedwald's formula. LDL $=$ total cholesterol(HDL+VLDL).Serum $\beta$-hCG is determined by CLIA (Chemiluminescent immuno assay).

All parameter values will be recorded. All patients was followed till delivery and observed for development of PIH.PIH is defined as BP $\geq 140 / 90$ after 20weeks of gestational age with or without proteinurea in previously normotensive women measured on two occasions at least 6hours apart Results so obtained was evaluated and analysed statistically.

\section{RESULTS}

Among the study group $38.15 \%$ were primi gravida and $61.85 \%$ were multi gravida. $3.47 \%$ had abortions. $35.26 \%$ delivered by caesarean section and $61.27 \%$ delivered by normal vaginal delivery. $8 \%$ developed mild PIH, $4 \%$ developed severe PIH while $88 \%$ remained normotensive.

Among total population 40 women belong to age group less than 20 years, among them $82.5 \%$ remained normotensive, $10 \%$ developed mild $\mathrm{PIH}, 7.5 \%$ developed severe PIH. 86 women belong to age group between 2125 years, among them $91.9 \%$ remained normotensive, 4.7\% developed mild PIH, 3.5\% developed severe PIH.42 women belong to age group between 26-30 years, among them $92.5 \%$ remained normotensive, $7.1 \%$ developed mild PIH. 5 women belong to age group more than 30 years, among them $20 \%$ remained normotensive, $60 \%$ developed mild PIH and 20\% developed severe PIH.

In our study we have found that those women belonging to higher age group have greater chance of developing PIH. 66 women were primi Gravida, among them $80.3 \%$ remained normotensive, $10.6 \%$ developed mild $\mathrm{PIH}$ and 9.1\% developed severe PIH. 107 women were multi gravida, among them $92.5 \%$ remained normotensive, $6.5 \%$ developed mild PIH, $0.9 \%$ developed severe PIH. Primi Gravida are more prone for developing PIH.

138 women who had $\beta-\mathrm{HCG}$ values less than 30,000 remained normotensive 9 women with $\beta$-HCG between $30,000-40,000,77.8 \%$ remained normotensive, $22.2 \%$ developed mild PIH. 3 women with $\beta$-HCG values between 40,000-50,000, all remained normotensive. 4 women with $\beta$-HCG values between 50,000-80,000, 50\% remained normotensive while $50 \%$ developed mild $\mathrm{PIH}$. 8 women with $\beta$-HCG values between 80,000-1 lakh, $12.5 \%$ remained normotensive while $87.5 \%$ developed mild PIH. Among 11 women with $\beta$-HCG values more than 1 lakh, $9.1 \%$ remained normotensive, $27.3 \%$ developed mild PIH, 63.6\% developed severe PIH. 
Women with elevated levels of $\beta$-HCG (more than 500000) had more chance for developing PIH.

151 women with TC values less than 180, 97.4\% remained normotensive, $2 \%$ developed mild $\mathrm{PIH}, 0.7 \%$ developed severe PIH. 16 women with TC value greater than $200,12.5 \%$ remained normotensive, $50 \%$ developed mild PIH and $37.5 \%$ developed severe PIH.

Women with elevated TC values had more chance for developing PIH.

135 women with TG values less than 160, 98.5\% remained normotensive, $0.7 \%$ developed mild $\mathrm{PIH}, 0.7 \%$ developed severe PIH. 14 women with TG value greater than 200, 57.1\% developed mild PIH and $42.9 \%$ developed severe PIH. Women with elevated TG values had more chance for developing PIH.
132 women with LDL values less than 105, 97.7\% remained normotensive, $1.5 \%$ developed mild $\mathrm{PIH}, 0.8 \%$ developed severe PIH. 14 women with LDL value greater then 130, $14.3 \%$ remained normotensive and 50\% developed mild PIH, 35.7\% developed severe PIH. Women with elevated LDL values had more chance for developing PIH.

153 women with VLDL values less than 35, 96.7\% remained normotensive, $2.6 \%$ developed mild PIH, $0.7 \%$ developed severe PIH. 5 women with VLDL value greater then 45, 20\% developed mild PIH, $80 \%$ developed severe PIH. Women with elevated VLDL values had more chance for developing PIH.

Table 1: Altered lipid profile.

\begin{tabular}{|lllllll|}
\hline Lipid Type & Normal / PIH & N & Mean & SD & ANOVA & p \\
\hline TC & Normotensive & 152 & 157.85 & 12.12 & 134.25 & $<0.001^{* *}$ \\
\hline & Mild & 14 & 203.43 & 24.48 & & \\
\hline & Severe & 7 & 236.71 & 42.46 & & \\
\hline & Total & 173 & 164.73 & 24.74 & & \\
\hline TG & Normotensive & 152 & 137.91 & 16.55 & 122.50 & $<0.001^{* *}$ \\
\hline & Mild & 14 & 198.07 & 24.53 & & \\
\hline & Severe & 7 & 217.57 & 38.64 & & \\
\hline & Total & 173 & 146.00 & 28.72 & & \\
\hline HDL & Normotensive & 152 & 37.63 & 4.54 & 13.19 & $<0.001^{* * *}$ \\
\hline & Mild & 14 & 32.36 & 5.83 & & \\
\hline & Severe & 7 & 30.86 & 8.91 & & \\
\hline & Total & 173 & 36.92 & 5.20 & & \\
\hline LDL & Normotensive & 152 & 92.83 & 11.72 & 107.60 & $<0.001^{* *}$ \\
\hline & Mild & 14 & 131.46 & 22.34 & & \\
\hline & Severe & 7 & 161.40 & 41.88 & & \\
\hline & Total & 173 & 98.73 & 22.30 & & \\
\hline VLDL & Normotensive & 152 & 27.42 & 3.47 & 119.24 & \\
\hline & Mild & 14 & 39.61 & 4.91 & & \\
\hline & Severe & 7 & 44.46 & 8.75 & & \\
\hline & Total & 173 & 29.09 & 6.01 & & \\
\hline
\end{tabular}

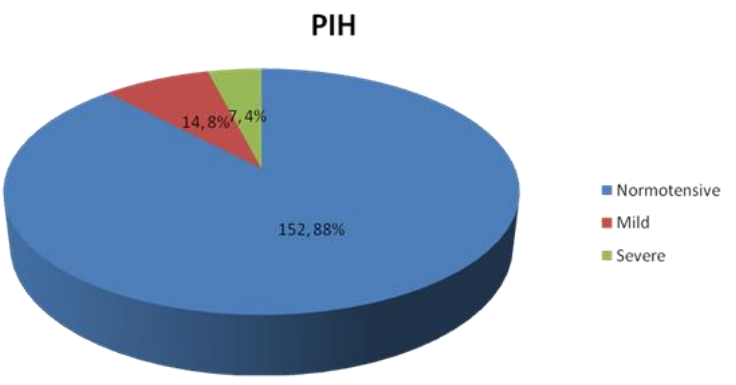

Figure 1: Incidence of PIH in altered lipid profile.

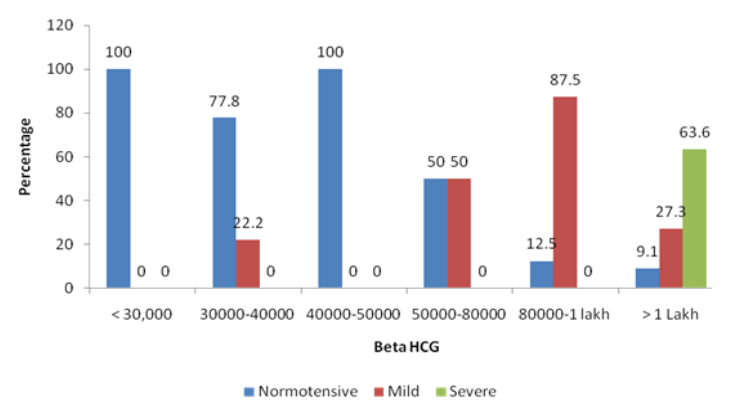

Figure 2: Incidence of PIH in relation to $\beta$-HCG. 
47 women with HDL values greater than 40, 93.6\% remained normotensive, $4.3 \%$ developed mild $\mathrm{PIH}, 2.1 \%$ developed severe PIH. 50 women with HDL value between 31-35, 90\% remained normotensive, $8 \%$ developed mild PIH. 2\% developed severe PIH. 15 women with HDL value less than $30,33 \%$ remained normotensive, $46.7 \%$ developed mild PIH. $20 \%$ developed severe PIH. Women with decreased HDL had more chance for developing PIH.

\section{DISCUSSION}

In our study women with elevated levels of $\beta-\mathrm{HCG}$ in early $2^{\text {nd }}$ trimester had more chance of developing PIH which is comparable to the study done by Chandra et al and Vidyabati et al. ${ }^{3,4}$ In our study 87.5 of women developed PIH if TC $>200 \mathrm{mg} / \mathrm{dl}$ and $85.7 \%$ if LDL more than $130 \mathrm{mg} / \mathrm{dl}$ ( $\mathrm{P}$ valve $<0.001)$ which in comparable with the study done by Vidyabati et at. ${ }^{4}$

In our study women who had TG more than $200 \mathrm{mg} / \mathrm{dl}$ $57.1 \%$ developed mild PIH $42.9 \%$ developed severe PIH (P Value <0.001). So almost all the 14 women developed $\mathrm{PIH}$ which is comparable with the meta analysis study published in BJOG by Gallos et al and Amar lal et al. ${ }^{5,6}$ Abnormal levels of TG is associated with pregnancy complication. ${ }^{7}$

The raised TG level increased atherogenic LDL concentration. The mean LDL Cholesterol and TG levels were significantly higher in the women who are likely to develop preeclampsia in future. Hyperlipidemia is of concern because it is associated with endothelial dysfunction. But increased HDL is likely to inhibit oxidation of LDL and thus protect the endothelium.

In our study women having low levels of HDL had more chance of developing PIH $66.7 \%$ of women with low HDL developed PIH which is comparable to study done by Vidyabati et al. ${ }^{4}$

So from this study we add evidence supporting that altered lipid profile (mainly hyper triglyceridaemia) and increased $\beta$-HCG as early predictors of PIH.

\section{CONCLUSION}

In our study we have observed a strong correlation between lipid profile and $\beta$-HCG levels to the development of PIH. Hence estimation of lipid profile and $\beta-\mathrm{HCG}$ in early second trimester can be a cost effective way in diagnosing PIH well in advance, because early identification of PIH still remains the corner stone to prevent maternal and fetal morbidity and mortality due to hypertensive disorders. Hence we conclude that maternal dyslipidemia and elevated maternal serum $\beta$ HCG at early second trimester are very good invasive predictors of PIH. However dyslipidemia mainly triglyceride levels seems to be a more effective marker in predicting PIH at early second trimester.

\section{Funding: No funding sources}

Conflict of interest: None declared

Ethical approval: The study was approved by the Institutional Ethics Committee

\section{REFERENCES}

1. Pregnancy hypertension (text book of Williams obstetrics (23 ${ }^{\text {rd }}$ edition) chapter 36; 2005:706-749.

2. Belo L, Caslake M, Gaffney D, Santow-silva A, Pereira-Leite L, Quintanilla A, et al. Changes in LDL size and HDL concentration in normal and preeclamptic pregnancies. Atherosclerosis. 2002;162(2):425-32.

3. Dodds L, Scott H, Chandra S, Watts C. unexplained elevated maternal serum $\alpha$-Feto protein and or hCG and risk of adverse outcomes-AJOG. 2003;189(3);775-81.

4. Vidyabati RK, Davina H, Singh NK, Singh W. Gyaneshwar-Serum $\beta$ hCG and lipid profile in early second trimester as predictors of Pregnancy induced hypertension. J Obstet Gynecol India. 2010;60(1):4450 .

5. Gallos ID, Sivakumar K, Kidby MD, Coomarasamy A, Thangaratinam S, Vatish M. Pre-eclampsia is associated with, and preceded by, hyper triglyceridaemia; a meta-analysis. BJOG. 2013;120:1321-32.

6. Dodani AL, Nakani K, Shaikh AW, Gurbakhshani AL, Dodani K. Assessment of lipid profile in Pre Eclampsia. Pjmhsonline.com.

7. Wiznitzer A, Mayer A, Novack V. Association of lipid levels during gestation with preeclampsia and GDM; a population based study. AJOG. 2009;201(5);482.e1-482.e8.

Cite this article as: Shanmugavadivu L, Sundari MKP, Devi P. Early predictors of PIH: serum $\beta$-HCG and lipid profile. Int J Reprod Contracept Obstet Gynecol 2016;5:4142-5. 